\title{
Políticas, acciones y gestión turística cultural. La ciudad de Lorca (Murcia, España) ${ }^{1}$
}

\author{
Policies, Actions and Cultural Tourism Management. City of \\ Lorca (Murcia, Spain)
}

\section{Aurelio Cebrián Abellán ${ }^{2}$}

Para citar este artículo utilice el nombre completo así:

Cebrián, A. (2015). Políticas, acciones y gestión turística cultural. La ciudad de Lorca (Murcia, España). Perspectiva Geográfica, 20(2), 365-390.

\section{Resumen}

Aborda la política turística cultural a escala administrativa local (la ciudad de Lorca, España), con énfasis en diferentes fórmulas de planificación integral a través de distintos modelos de gestión, que involucran a entidades administrativas superiores, y aporta dos tipos de turismo: patrimonial y de catástrofes; en segunda instancia, presenta las dificultades metodológicas para abordar ese frente, con fuentes también dispersas y poco homogéneas, que permiten aproximaciones y tendencias. El resultado es una política de turismo cultural específica, acompañada de un complemento sobrevenido: el terremoto de 2011 en Lorca, y el debate se plantea en la ligazón entre fortalezas y realidades conseguidas, y en la adaptación y mutabilidad que aporta una política turística cultural viva, marcada por la crisis económica nacional y las adversidades naturales, aprovechadas como recurso turístico.

Palabras clave: explotación patrimonial, gestión turística, planificación integral, política turística, resultados turísticos, tendencias turísticas, turismo local

\footnotetext{
1 Proyecto 18937/JLI/13 de la Fundación Séneca. Agencia de Ciencia y Tecnología de la Región de Murcia: El turismo en la revitalización del patrimonio histórico de Lorca: actores y estrategias.

2 Profesor Titular de Análisis Geográfico Regional. Departamento de Geografía y Ordenación del Territorio, Universidad de Murcia (España). aurelio@um.es
} 


\begin{abstract}
The study addresses the cultural tourism policy at the local administrative level, with a focus on the different variations of integrated planning across different management models, which involve superior administrative bodies and offer two tourism types: cultural-heritage related tourism, and a tourism linked to the effects of natural disasters (Lorca earthquake 2011). Secondly, the study addresses the methodological difficulties to approach the first point, due to disperse and few homogeneous sources, which however allow estimates and trends to be analyzed. The result is a particular cultural tourism policy accompanied by an additional unexpected fact, an earthquake. The current debate pays attention to the link between existing strengths and achievements, and the adaptation and mutability that engenders a cultural and lively tourism policy, marked by the national economic crisis and natural adversities exploited as a tourist resource.
\end{abstract}

Keywords: asset exploitation, tourism management, integrated planning, tourism policy, tourism performance, trends in tourism, local tourism 


\section{Introducción}

El paso de producto a destino turístico requiere un análisis de sus elementos principales, secundarios y complementarios. Por ello, los agentes y los factores turísticos, seleccionados por razón de espacio, son abordados en este trabajo con metodología cuantitativa, a partir de fuentes específicas, complementarias, regionales, municipales y del consorcio que gestiona el producto; unas globalizan datos y otras modifican cómputos, aunque permiten acercarse a la hipótesis de paso a destino turístico, esclarecer objetivos, confirmar debilidades $\mathrm{y}$ aproximarse a las fortalezas. Por otro lado, los estudios sobre elementos del sistema, agentes, factores y medios de análisis, y los de turismo cultural urbano español y gestión de ciudades históricas disfrutan de excelentes aportaciones: Troitiño Vinuesa (2006; 2007), Valenzuela Rubio, Vera Rebollo, Nogué, Antón, etc. Desde ambas bases, la metodología cuantitativa y los estudios de turismo urbano se analiza y revisa el producto Lorca Taller del Tiempo, con el patrimonio urbano artístico y cultural artístico y cultural como producto principal, una parte del variado legado histórico de la Comunidad de Murcia, cuya posición geográfica entre Castilla y el Mediterráneo (Figura 1) explica la proliferación de Bienes de Interés Cultural (BIC).
En la ciudad de Lorca, el factor primario también dimana de su emplazamiento doble, entre interior $\mathrm{y}$ costa y entre Levante y Andalucía, en el corredor de los ríos Segura y Guadalentín, vías históricas en forma de cruz (Figura 2), y hoy ejes regionales. A esa conjunción responde el asentamiento en el valle del Guadalentín de las culturas argárica, ibérica, romana, bizantina y visigoda. La ciudad pasaría de capital de la cora de Todmir al esplendor califal de los siglos VIII al $\mathrm{X}$, que contribuyó al auge urbano. En el siglo XVI, el control castellano la convertiría en una de las peninsulares más importantes. Con los Austrias se instaló la oligarquía ganadera, y la agraria a finales del siglo XVII, aprovechando el Real Canal de Murcia y los pantanos de Puentes y Valdeinfierno; es la etapa del gótico tardío, renacimiento y barroco. Y con la fase liberal llegarían las grandes transformaciones urbanas. De esa evolución hay en herencia un patrimonio de 660 elementos, con 28 monumentos, 15 BIC.

El primer objetivo de análisis es un producto que aprovecha dos recursos patrimoniales: el castillo, imagen de la ciudad, con rehabilitaciones municipales desde 2003 (Plan Especial de Protección de la Muralla de Lorca, y del entorno, con el Plan Integral para los Barrios Altos de Lorca), y el casco urbano antiguo, Conjunto Histórico Artístico, con baja calidad ambiental por el deterioro de la es- 


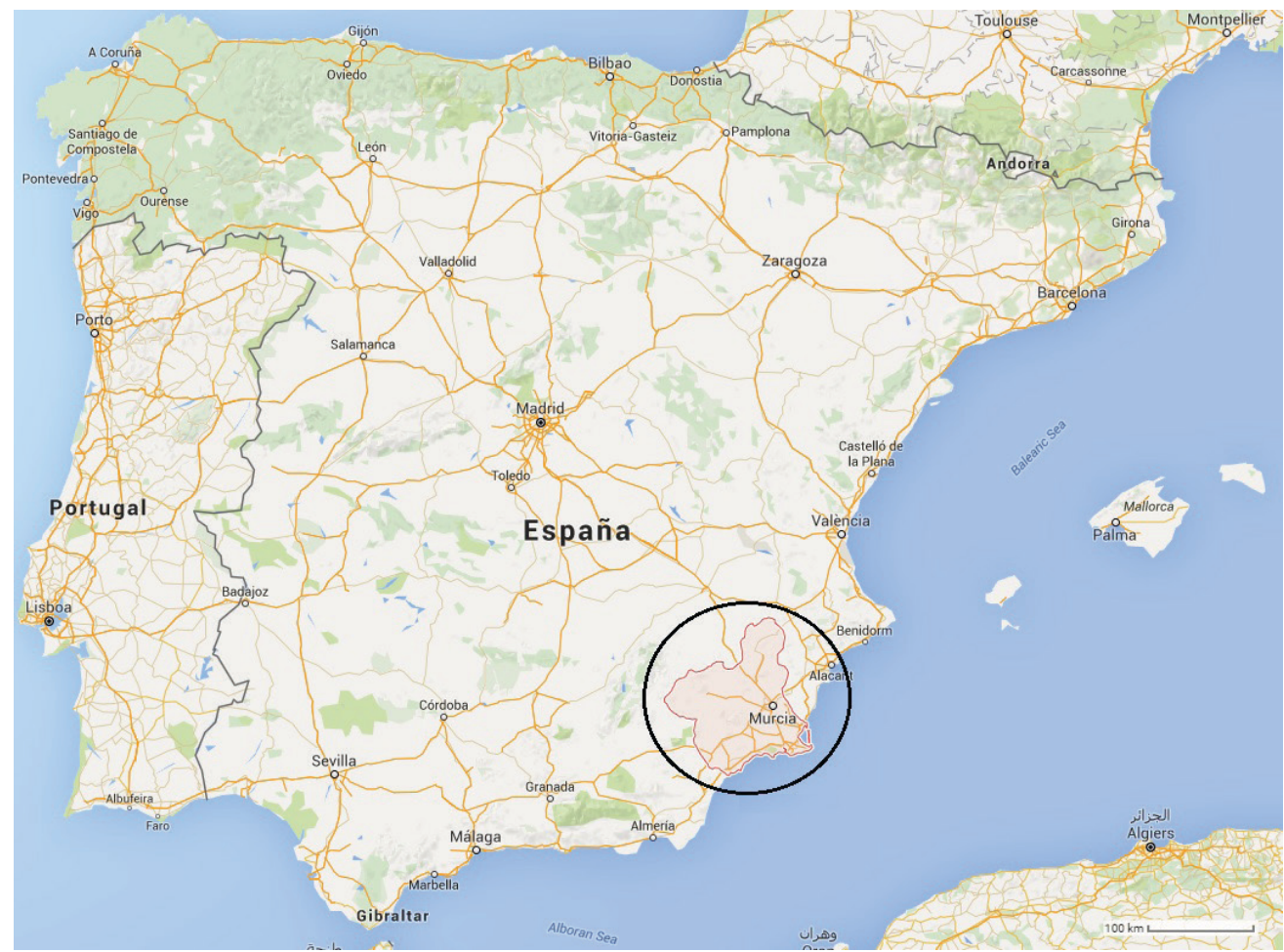

Figura 1. Emplazamiento de la región de Murcia en España Fuente: Adapatado de Google Maps.

cena urbana, especulación del suelo. Urge la conservación (identidad del paisaje urbano, valores culturales) y adaptación a las necesidades urbanas (rejuvenecimiento de los residentes, revitalización comercial, etc.).

Otro objetivo está centrado en dos agentes turísticos. El primero es el manejo o tratamiento del producto, con planificación sobre directrices transferidas a las Comunidades Autónomas (CCAA) y entidades locales, y secuencia similar de fondos. En Lorca, un consorcio gestiona los planes estratégicos, alterados tras los efectos del terremoto de 2011. El segundo es el turista, mayoritario nacional y de proximidad, y de corta estancia.

Los últimos objetivos corresponden a los factores de demanda: las iniciativas culturales (que incorporan incrementos de visitantes), niveles de ocupación y necesidad de mejora de la calidad, etc. Los datos manejados aportan resultados laborales y dotaciones, pero no el impacto económico sobre la ciudad. 


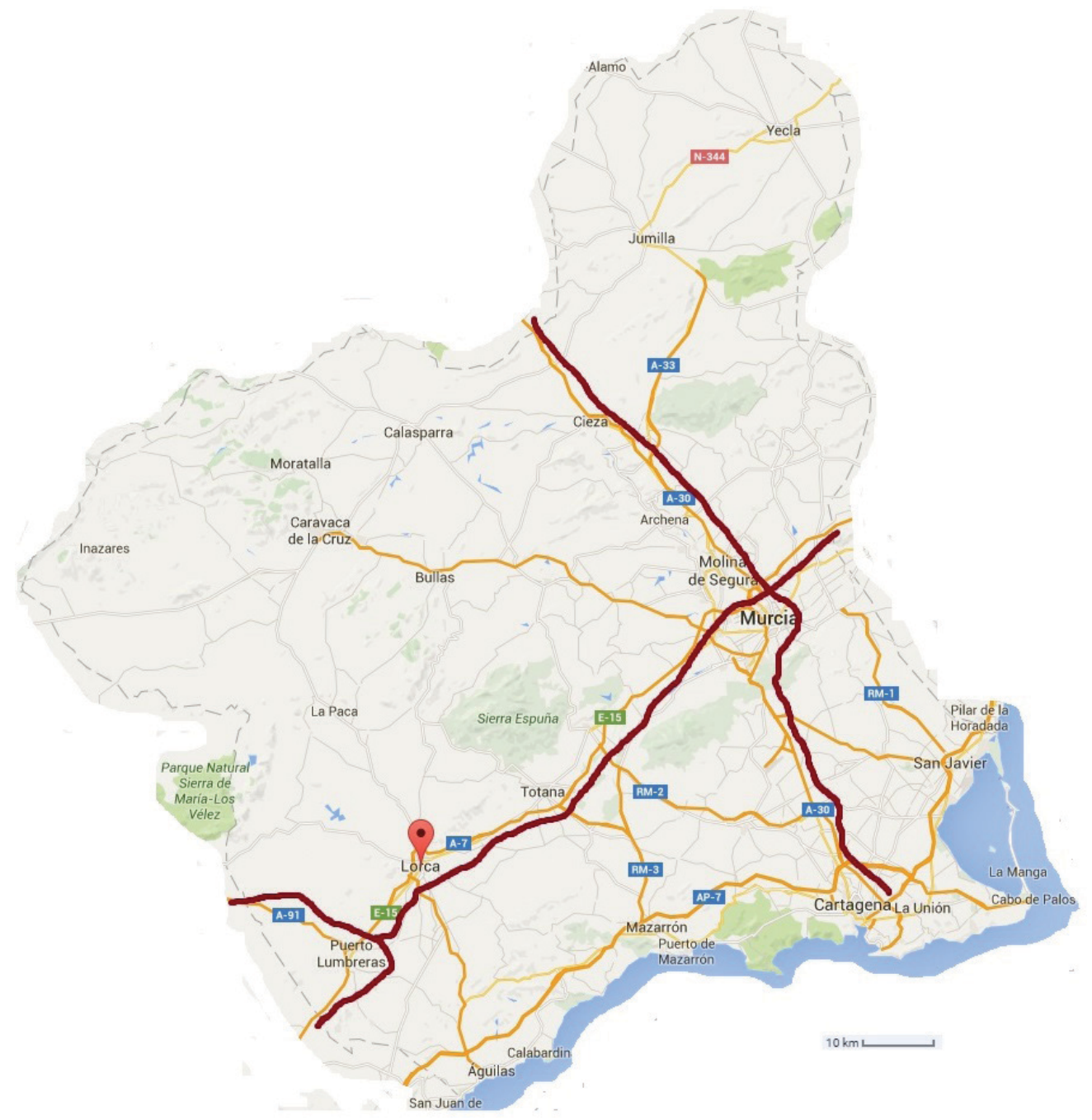

Figura 2. Comunidad de Murcia y ejes sobre los corredores básicos de comunicación Fuente: Adapatado de Google Maps.

2. Protección patrimonial y acción en turismo cultural

El paisaje urbano puede ser producto turístico, como lo indica la Estrategia del paisaje de la Región de Murcia (CARM, 2008), con extensión a Lorca en un subproyecto. El patrimonio cultural urbano es parte del conjunto paisajístico, y requiere de protección, rehabilitación y ordenación (Cebrián, 2002); sobre él se desarrolla el turismo cultural como sistema productivo singular (Vera, 2005), que exige 
una planificación integral, incluida la turística cultural: diseño a largo plazo, ajuste a cambios y modos de gestión, coordinación de sectores y agentes. La organización de espacios y conjuntos paisajísticos mediante planes es una responsabilidad pública, y también la organización turística cultural, que aprovecha paisaje y patrimonio, una secuencia contenida en el producto analizado.

La base es la protección patrimonial, ya abordada desde las políticas institucionales, normativas y acciones europeas y nacionales (Cebrián, 2004 a). Resalta la acción de las Iniciativas Comunitarias, transformadas en programas operativos de turismo cultural en Murcia, Cartagena y Caravaca de la Cruz, con fondos y mecenazgo de fundaciones e instituciones. URBAN (2008-2015) actúa en Lorca sobre los barrios altos, con inversión municipal y del FEDER de 9,6 millones de euros. Ya en España las acciones arrancan de planes específicos ${ }^{3}$, con aportaciones financieras comunitarias y centrados en la revisión de estrategias, formulación de políticas, etc., que conforman las directrices de los planes regionales.

El análisis siguiente se basa en la descentralización de programaciones $\mathrm{y}$ acciones a escala regional y local (Cebrián, 2004a). Las CCAA dispo-

3 Plan de Turismo de España Horizonte 2020, Promoción Internacional del Turismo Cultural 2012-2012, y Nacional e Integral de Turismo 2012-2015. nen de competencias para la conservación, promoción y ordenación turística ${ }^{4}$, las cuales desarrollan en documentos estratégicos. En Murcia parten del Estatuto de Autonomía ${ }^{5}$, pero la consideración de interés cultural a los bienes históricos está en la Ley de Ordenación y Protección del Territorio de la Región de Murcia $^{6}$. La explotación parte de leyes básicas $^{7}$, de las que emana el Plan Director de Turismo de la Región de Murcia 2006-2012, orientado a potenciar los productos turísticos urbanos y culturales (Cebrián, 2004 b). Del Plan Estratégico de la Región de Murcia 2007-2013 nacieron tres Productos Turísticos Integrados (CONSULTUR, 1996; CARM, 1997, y Cebrián, 2004c), con recursos del FEDER para la recuperación patrimonial; dos en la marca Murcia Tierradentro: 'Cartagena Puerto de Culturas' (Cebrián, 2005) y 'Lorca, Taller del Tiempo', y, Caravaca Ciudad Santa, (Cebrián, 2006; 2008). La Estrategia de Desarrollo Turístico de la Región de Murcia 2010-2015 y el Plan Estratégico de la Región de Murcia 2014-2020 (CARM, 2012) alumbrarían una planificación desti-

\footnotetext{
4 Artículo 148.18 de la Constitución Española.

5 Ley Orgánica 4/1982 /Artículos 10, 12 y 15.

6 Ley $4 / 92$ de 30 de Julio.

7 4/1990 de Fomento del Patrimonio Histórico de la Región de Murcia, 4/2007 de Patrimonio Cultural de la Región de Murcia y 1/2991 del Suelo de la Región de Murcia. La última, 12/2013 de Turismo de la Región de Murcia, modificada por la Ley 11/2014.
} 
nada a transformar el turismo cultural en actividad económica principal, a través de ejes (Figura 3), de los que emanarían diez productos turísticos (Murciaturística, 2011), con el cultural de Lorca.

\section{Dinamizadores de las zonas turísticas}

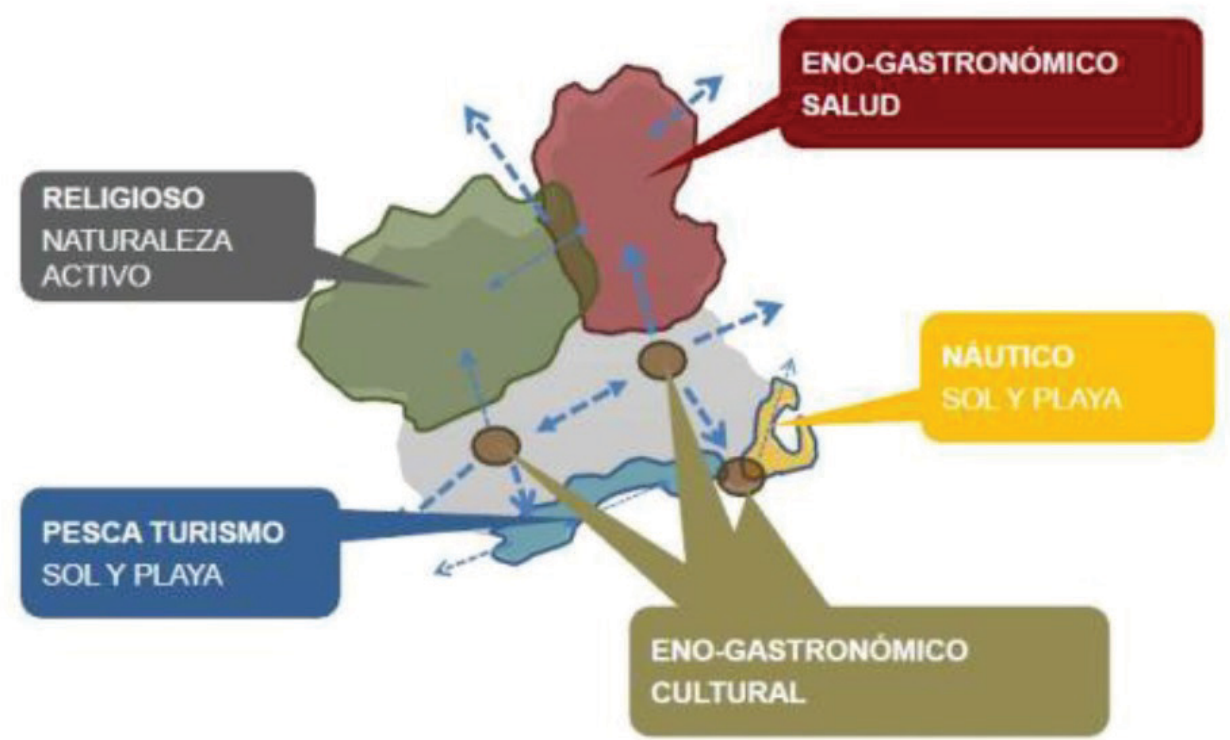

Figura 3. Ejes turísticos por sectores territoriales

Fuente: Estrategias de desarrollo turístico de la Región de Murcia 2010-2015. Murciaturística (2011).

El traspaso a entes locales de competencias autonómicas sobre protección patrimonial y actividades culturales aportó el Municipio Turístico, una fórmula acabada en Murcia, de la que derivó la proliferación de consorcios o patronatos municipales de turismo y empresas públicas. Puede decirse que la planificación integral del turismo en esta Comunidad arranca con los tres Planes de Desarrollo Territorial $^{8}$, y también con la confor-

8 Noroeste, Nordeste y Sierra Espuña. mación de consorcios ${ }^{9}$, tantos que la Asociación de Consorcios Turísticos de la Región de Murcia (Murcia Data) logró reunir a 32. Los Planes de Dinamización Turística (Producto Turístico de Lorca, 2006 ampliado a 2011), de Excelencia y de Calidad (en Lorca con el Sistema Integral de Calidad Turística Española en Destino) ya fueron gestionados por

9 Murcia Cruce de Caminos, Sierra Minera, Lorca Taller del Tiempo, Turismo de Salud de la Región de Murcia, Cartagena Cultural... 
consorcios; pero la crisis económica demostró escasez de proyectos públicos, exceso de marcas turísticas, inversiones de baja rentabilidad..., y obligó al reajuste, con eliminación de 23 entes (siete han pasado a locales, como Lorca Taller del Tiempo), 11 consorcios y 4 empresas públicas turísticas.

\section{Consorcio y sociedad anónima en la ciudad de Lorca. La acción turística cultural}

El Plan Estratégico para el Desarrollo del Turismo Cultural en Lorca (1998) alumbró el Consorcio para el Desarrollo Turístico y Cultural de Lorca (Consejería de Economía y Hacienda, 1998), integrado por administraciones y organizaciones ${ }^{10}$, que se volcó en la rehabilitación del castillo. El Plan de Dinamización del Producto Turístico de Lorca (aprobado en 2004, y efectivo en 2006) (Web: Plan de dinamización del producto turístico de Lorca) estaría enfocado a un destino turístico emergente, gestionado por Lorca Taller del Tiempo, un consorcio ${ }^{11}$ real desde 2003. Después pasaría a LORCATUR, una empresa munici-

\footnotetext{
10 Gobierno regional, Ayuntamiento de Lorca, Cámara de Comercio e Industria y Confederación Comarcal de Organizaciones Empresariales de la ciudad.

11 Secretaría General de Turismo del Ministerio de Industria, Turismo y Comercio, Consejería de Cultura y Turismo de la Comunidad Autónoma de la Región de Murcia, Ayuntamiento de Lorca y Confederación Comarcal de Organizaciones Empresariales de Lorca.
}

pal encargada de gestar un producto cultural, potenciar el uso patrimonial y atraer inversión (Lirón, 2012).

Las dos primeras metas se centraron en la organización del patrimonio, apoyadas en una funcionalidad militar primaria musealizada, presidida por el castillo, una alcazaba islámica (713-1244) (Martínez, 2004); en 2003 finalizó su restauración, que aportó 'La Fortaleza del Sol', premio al Mejor Producto de Turismo Cultural en la Feria Internacional del Turismo (FITUR) en 2005. Esa función se complementaría con la escena Barroca del Conjunto Histórico-Artístico, con la Plaza de España y el Ayuntamiento, de los siglos XVII-XVIII (Segado, 2012), y la Colegiata de San Patricio (1536-1780), renacentista con fachada barroca (1694), obra maestra del momento. Sobre esa estructura, militar y urbana, se aplicó el componente de interpretación y los factores de singularidad y adaptación. El espacio urbano se ajustó a un eje que cruzaría el centro histórico, con cuatro itinerarios culturales ${ }^{12}$ (Jiménez, 2003) y museos $^{13}$. Pero el castillo sería la clave, con exposiciones permanentes: Máquina del tiempo, Rincón arqueológico, etc.; actividades culturales (multimedia, el programa Espiralia de

\footnotetext{
12 Entre el cielo y el suelo, Tiempo de contratiempos, La ciudad de los cien escudos y Tiempo de devoción.

13 Arqueológico Municipal de Lorca, Palacio de Guevara, Hermandad de Labradores, Paso Azul, Paso Blanco, Paso Encarnado y Nicolás Salzillo.
} 
conciertos y teatro...) y de aprendizaje (historia); y servicios propios, a los que se han añadido los del Parador Castillo de Lorca ${ }^{14}$, con salones para turismo congresual, más la restauración arqueológica en el inmueble y el entorno ${ }^{15}$, por la que en 2014 recibió el premio Travellers Choice Paradores, de TripAdvisor, como mejor de España.

En 2011, dos terremotos, de 4,5 y 5,1 grados en la escala de Richter (Instituto Geológico de Cataluña et al, 2011) afectaron una parte de la ciudad y 56 edificios históricos (Dios de la Hoz, 2012). Para atender la urgencia de la restauración se creó el Plan Director de Recuperación del Patrimonio Cultural de Lorca (2011), promovido por la Dirección General de Bellas Artes y Bienes Culturales del Ministerio de Cultura, con un plazo de ejecución de cinco años. Se ha centrado en los BIC, viviendas relevantes del siglo XIX y principios del XX y casco histórico. En 2015 ya están rehabilitados el $95 \%$ de los BIC. Para la Concejalía de Turismo, la inversión real ha sido de $18,7 \mathrm{mi}$ llones de euros, de los 23,7 prestados por el Banco Europeo de Inversiones. Los efectos del sismo fueron aprove-

14 El número 94 de la Red Nacional, realizado con una inversión de 33 millones de euros y abierto en 2012, con retraso debido al terremoto del año anterior.

15 Sinagoga del siglo XV, casas judías, muralla almohade del siglo XIII y restos de construcciones islámico-califales de los siglos X-XI. chados para el diseño de un producto turístico ligado a las catástrofes. En junio de 2011 se gestó la ruta Lorca, abierta por restauración, orientada a la comprensión de la incidencia de las fuerzas naturales sobre el patrimonio, y para comprobar el proceso de rehabilitación. Hay referencias previas, como la catedral de Vitoria, con su Abierto por Obras, pero aquí la directriz es la respuesta a los efectos de la naturaleza. La ruta, guiada y de grupo, recibió en FITUR el premio del Grupo Excelencias 2012.

\section{Efectos turísticos}

Para el Plan de Dinamización del Producto Turístico de Lorca (2004), cada administración o entidad aportó la tercera parte de los fondos, con un total de 2,6 millones de euros, aunque Lorca Taller del Tiempo gestionó, hasta 2012, gastos corrientes de diez millones. Organizado el patrimonio, la meta era triple: atracción turística, con previsión para 2006 de 141.000 turistas/año; generación de empleo, con 50 puestos esperados, e impacto económico en la ciudad de unos seis millones de euros/año. Los datos permiten aproximarse a los dos primeros frentes.

El estudio de un agente clave, el turista cultural, se realiza con fuentes estadísticas directas, complementarias y encuestas de Lorca Taller del Tiempo. Las fuentes presentan alguna 
alteración de registro y variación de conceptos. Para completarlas se utilizaron dos estadísticas adicionales: las regionales, que incluyen a toda la Comunidad (demanda cultural) y no desagregan datos por subconceptos (tipo de alojamiento) (Unidad de Estudios y Estadísticas, 2004) o padecen dispersión (flujos turísticos), y las municipales, que globalizan resultados (la ocupación hotelera incluye a otra entidad municipal, las pernoctaciones son conjuntas de ciudad y playa, etc.). Objeto de un análisis diferenciado sería la repercusión sobre el turismo cultural de los múltiples eventos de la ciudad ${ }^{16}$.

Una fuente directa para el análisis del turista es la Oficina de Turismo de Lorca (Concejalía de Turismo y
Estadística, 2015), que incluye una actividad turística también directa, los solicitantes de información. Permite obtener la cuantía y tendencia del flujo. La secuencia existente (20062014) indica una recepción total de 206.212 visitantes, un $47 \%$ más de los 141.000 pretendidos para 2006, pero descendente en la serie (Figura 4). La composición la aporta una encuesta de la misma fuente: un 58,8 $\%$ son nacionales y mayoritariamente de proximidad. La tendencia de flujos entre las fechas citadas marca un repunte en 2010, con la iniciativa cultural Lorca, luces de Sefarad ${ }^{17}$. Entre los extremos de la serie, la pérdida es del $54,8 \%$, equiparada entre nacionales $(57 \%)$ y extranjeros (56,2 \%). La razón de la caída está en la crisis económica.

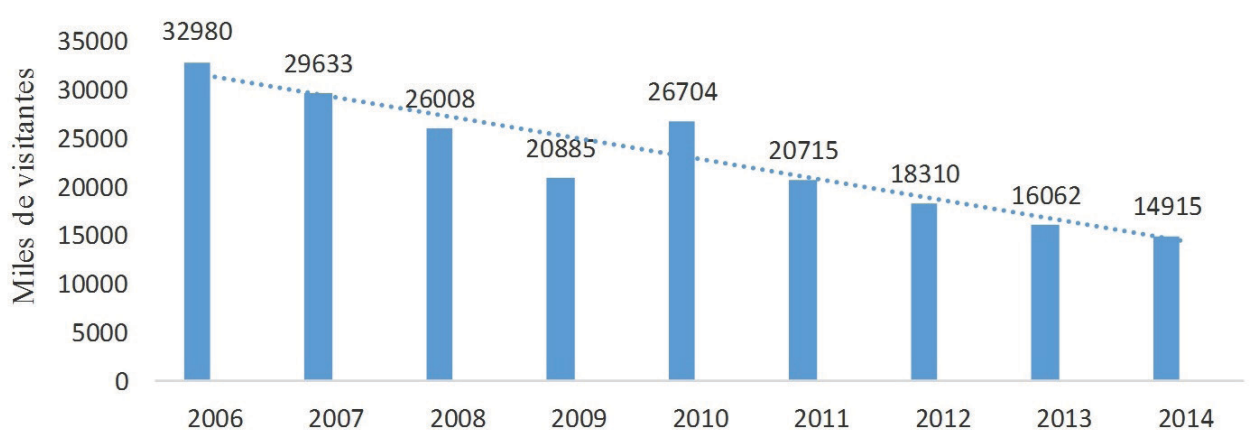

Figura 4. Visitantes y turistas de origen regional, nacional y extranjero

Fuente: Elaboración propia con base en Concejalía de Turismo y Estadística del Ayuntamiento de Lorca (2015).

\footnotetext{
16 La Semana Santa de Lorca (de Interés Turístico Internacional), ferias (Caballo, Artesanía de la Región de Murcia -con más de 100.000 visitantes-, Flor Cortada, Planta Ornamental y Afines de la Región de Murcia), eventos (Semana Nacional del Ganado Porcino), fiestas patronales, etc.
}

17 Sobre la cultura judía en el sureste español (siglos XIII-XV), tras el descubrimiento de la sinagoga del castillo. 
Para 2014, la fuente citada incluye otras iniciativas culturales. Las encuestas sobre visitas nocturnas a la Lorca Burguesa, guiadas y en inglés, incrementan el número de extranjeros, hasta llegar al $53 \%$, y las actividades culturales de verano en el casco histórico aportan 12.000 visitas, con un $63 \%$ de británicos y franceses, mientras el $24 \%$ de nacionales son de Madrid, Barcelona y Valencia. El 50,9 \% son familias que se desplazan en viaje particular, más colectivos de 45-60 y 30-45 años, con similar llegada. Lo significativo es que para el 98,4 \% el motivo de la visita es esencialmente cultural.
Otra fuente directa es Lorca Taller del Tiempo, con datos desagregados que permiten analizar el turismo senior, en viajes organizados, con 20.881 visitas totales entre 2003 y 2014. Es un segmento poco representativo sobre el total de visitas. La secuencia es oscilante hasta 2007 y descendente desde 2011 a niveles casi iguales a los iniciales. Pero la ganancia en la serie citada es del $84 \%$ (Figura 5), sorprendente al coincidir con la caída de subvenciones públicas a asociaciones de jubilados y centros de la mujer.

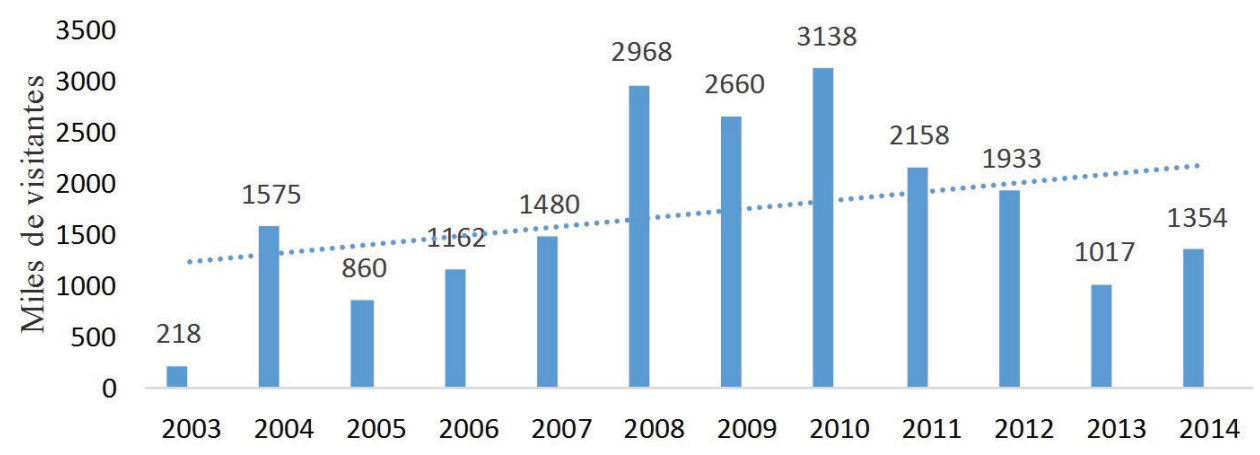

Figura 5. Evolución total de visitantes y turistas senior

Fuente: Elaboración propia con base en Lorca Taller del Tiempo (2015).

La misma fuente aporta referencias de Lorca, abierta por restauración, visita grupal y guiada. Del año del terremoto (2011) al siguiente, los visitantes pasaron de 3.376 a 5.664 , con mayoría de regionales; pero la venta de entradas fue muy escasa (830), y descendente desde 2012 (Figura 6), por la casi supresión de ayudas a viajes escolares y visitas formativas y culturales. No es extraña la tendencia, pero sí lo es la floja demanda del producto. 


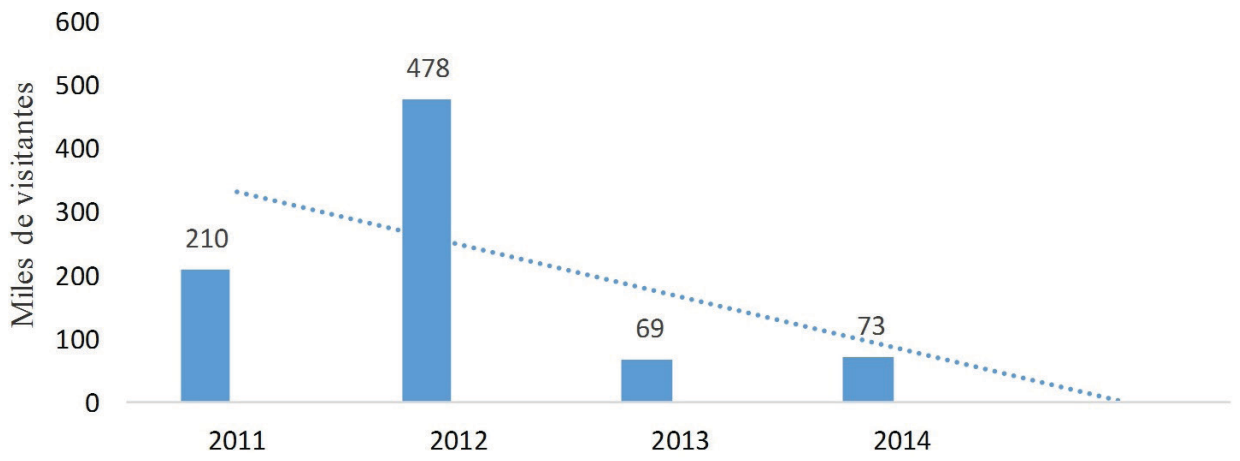

Figura 6. Visitantes a Lorca, abierta por restauración

Fuente: Elaboración propia con base en Lorca Taller del Tiempo (2015).

Los datos de Lorca Taller del Tiempo pero con una clara caía desde 2009, permiten comprobar el alcance de debida a los efectos del terremoto una actividad turística directa, la sobre el patrimonio visitable (Figura forma de mostrar el patrimonio. 7). La tendencia en la serie abordada Desde 2003 a 2014 el total de usua- es de mantenimiento. rios del tren cultural fue de 87.521,

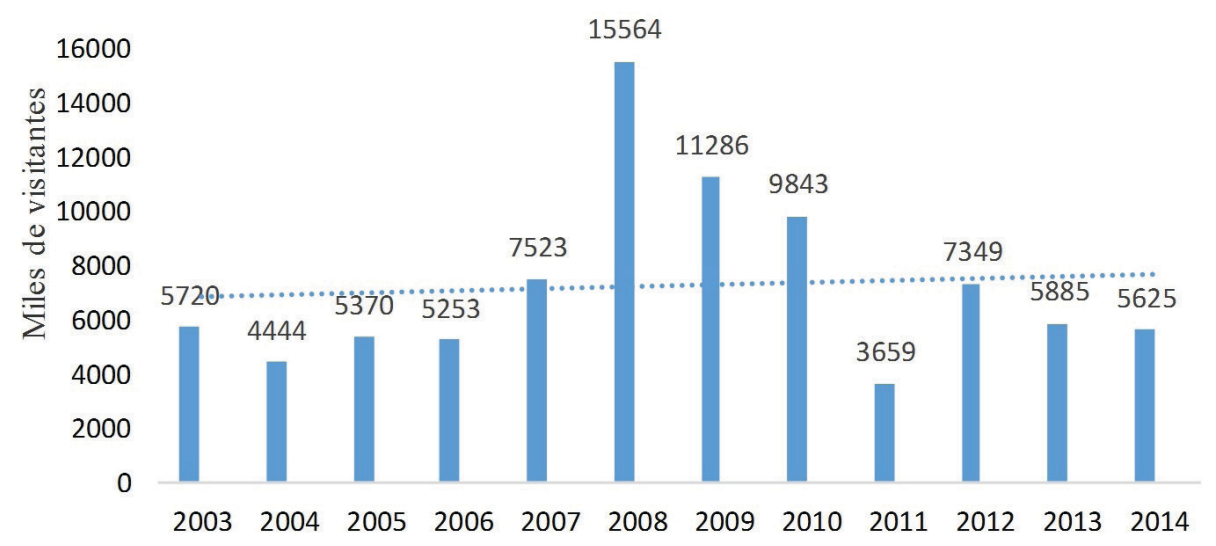

Figura 7. Total de usuarios del Tren Cultural

Fuente: Elaboración propia con base en Lorca Taller del Tiempo (2015).

La organización y oferta del producto primario, el patrimonio, puede ser analizada con la citada fuente, que permite comprobar la demanda. Por razón de espacio se opta por la más alta, La Fortaleza del Sol, que 
contabiliza 880.371 entradas totales entre 2003 y 2014, y una media anual de 73.364 (Figura 8). Los datos corroboran el atractivo del emblema turístico, sin necesidad de información en oficinas de turismo. Los resultados más flojos coinciden con el terremoto, que afectó estruc- turas y obligó al cierre parcial. El remonte posterior se relaciona con las rehabilitaciones (murallas y torre Alfonsina) y la apertura del parador. Entre las mismas fechas, la tendencia es sostenida, incluso durante los años más duros de la crisis económica.

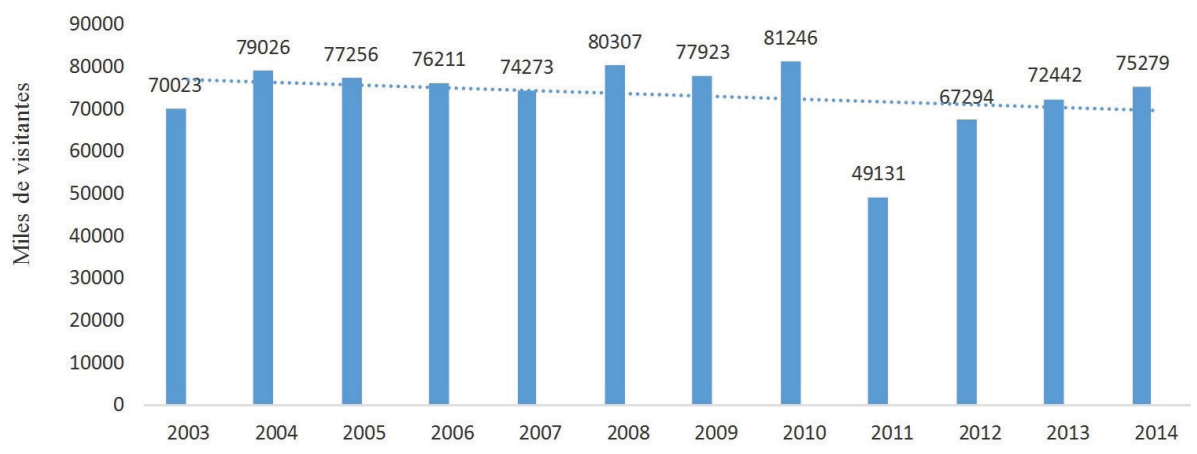

Figura 8. Total de visitantes por año a la Fortaleza del Sol Fuente: Elaboración propia con base en Lorca Taller del Tiempo (2015).

Lorca Taller del Tiempo permite también comprobar la demanda de espacios de la cultura urbana. Se opta por la más elevada, el Museo del Paso Blanco, que alberga el patrimonio relacionado con la Semana Santa; ha recibido 70.985 visitas entre 2003 y 2014 (Figura 9), con doble caída: desde 2007, por los efectos de la crisis, y desde 2011, por los del terremoto sobre el conjunto de Santo Domingo (Cartagena, 2012). Hasta la primera fecha, la subida fue del $39 \%$, y desde entonces el descenso ha llegado al $93 \%$. La secuencia de pérdidas es patente en la línea de tendencia entre esas fechas.
Agente clave del sistema turístico es la dotación de destino, analizada desde una fuente directa regional, la Unidad de Estudios y Estadísticas (Región de Murcia, 2015). La oferta es más amplia $^{18}$, pero interesa la urbana, suficiente por la escasa demanda. Entre 2003 y 2014 se da un incremento de plazas hoteleras del $26 \%$. Los registros de la Concejalía de Turismo, referidos a hoteles y pensiones en el municipio, aportan una subida en la serie de 57 plazas, la diferencia entre el cierre de dos hoteles y la apertura del parador.

18 El municipio dispone de veintiocho casas rurales (175 plazas), un camping (135), ocho apartamentos turísticos (35) y tres albergues (177). 


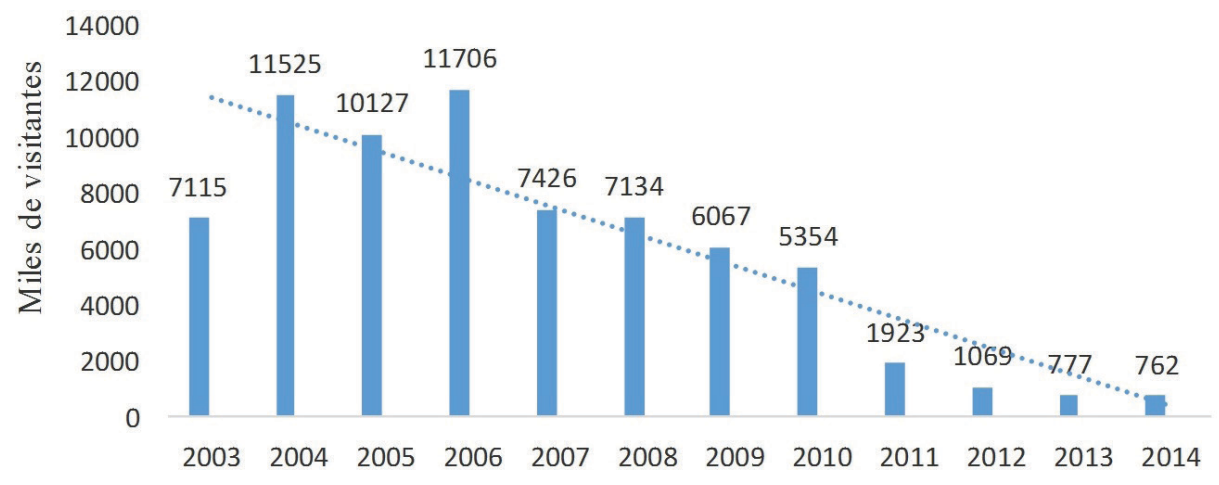

Figura 9. Total de visitantes al Museo del Paso Blanco

Fuente: Elaboración propia con base en Lorca Taller del Tiempo (2015).

La dotación de destino no sorteó mal la crisis hasta 2015, manteniendo la categoría media y baja de la oferta (a excepción del nuevo parador), cuando han cerrado dos hoteles, con la pérdida de 98 plazas.

La ocupación puede encontrarse en la estadística de registros hoteleros del Ayuntamiento de Lorca, que señala una subida del 40,7 \% entre el primer cuatrimestre de 2000, antes del inicio del proyecto, y el correspondiente de 2011, último dato disponible. La distribución temporal carece de referencias en algunos hoteles, y en otros hay porcentajes. La ocupación está liderada por el mes de septiembre (Figura 10), por la aportación de las fiestas de la ciudad, las ferias regionales y por semana santa; en el Parador es del 43,6 \%, ahora por los precios más elevados. Hay ascensos por meses (relacionados con eventos ya citados), ausencia de estacionali- dad marcada y casi la mitad del año con ocupación inferior al $50 \%$, que confirma a la ciudad como turística de paso. La ausencia de otra contabilidad no permite evaluar el impacto económico.

Respecto a la creación de puestos de trabajo, la plantilla media ha sido de 25 empleados, la mitad de los esperados para 2006, con un $80 \%$ de contratos indefinidos (locales el $92 \%$ ), y 375 empleos indirectos. Por último, las diferentes fuentes manejadas no permiten confirmar el impacto económico real del turismo cultural sobre la ciudad, estimado por la entidad gestora en seis millones de euros/año, y tampoco IMPACTUR (2013) aporta datos desagregados.

\section{De las expectativas a la prospectiva}

Si un destino turístico es un subsistema integrado por elementos 


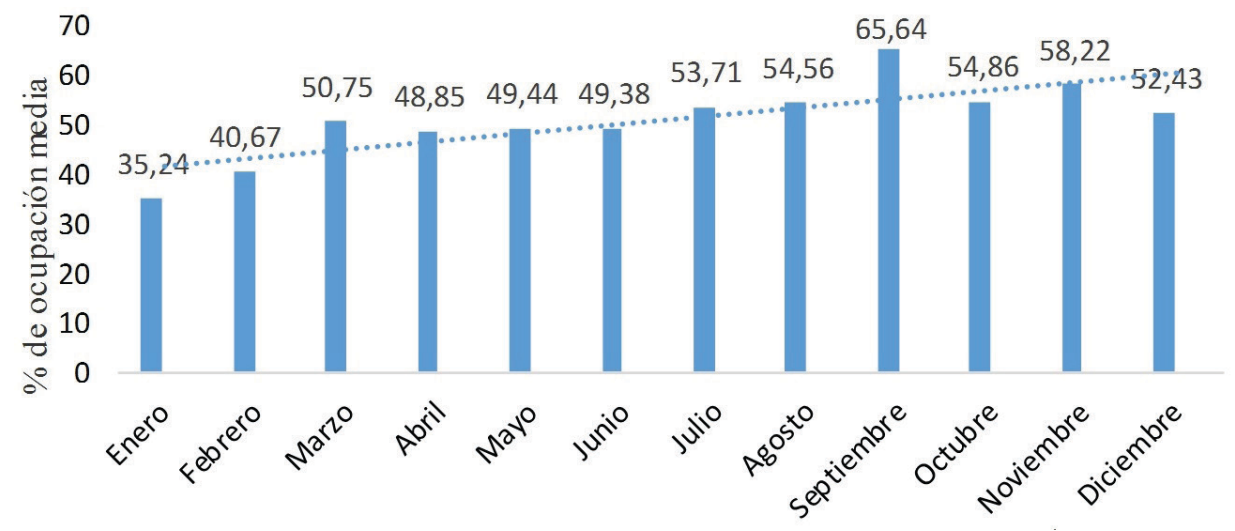

Figura 10. Porcentaje de ocupación media hotelera por meses (2006-2014)

Fuente: Elaboración propia con base en Concejalía de Turismo y Estadística del Ayuntamiento de Lorca (2015).

espaciales (recursos territoriales, infraestructuras, etc.), administrativos (legislación, políticas) y productivos (agentes, inversión, etc.), más sus interrelaciones y efectos sectoriales geográficos, para Lorca la respuesta es que lleva adelantado camino para su configuración, y que restan metas por alcanzar. Los análisis interno y externo muestran las fortalezas disponibles y debilidades pendientes, entre las que se destacan las fundamentales, por la evidente limitación de espacio.

Tabla 1. Análisis interno

\begin{tabular}{|c|c|c|}
\hline & FORTALEZAS & DEBILIDADES \\
\hline $\begin{array}{l}\text { ANÁLISIS } \\
\text { INTERNO }\end{array}$ & $\begin{array}{l}\text { - Capacidades institucionales } \\
\text { - Clima y emplazamiento geográfico } \\
\text { - Crecimiento económico y de la } \\
\text { ciudad, con incorporación de uni- } \\
\text { versidad } \\
\text { - Actualización productiva de la } \\
\text { artesanía } \\
\text { - Amplitud de recursos culturales } \\
\text { - Recursos culturales rehabilitados } \\
\text { - Actividades culturales } \\
\text { - Afiliación potencial a entidades y } \\
\text { acuerdos potenciales }\end{array}$ & $\begin{array}{l}\text { - Incidencia de la crisis económica y } \\
\text { terremoto } \\
\text { - Crisis social y baja cualificación } \\
\text { laboral } \\
\text { - Necesidad del sector artesanal } \\
\text { - Repercusión relativa del papel de } \\
\text { frontera } \\
\text { - Dispersión de recursos culturales } \\
\text { - Casco histórico con deterioros } \\
\text { - Baja incidencia del turismo de } \\
\text { catástrofes } \\
\text { - Necesidad de oferta del ámbito } \\
\text { geográfico próximo } \\
\text { - Consumo turístico temporal escaso }\end{array}$ \\
\hline
\end{tabular}

Fuente: Elaboración propia. 
Entre las fortalezas internas destaca la completa normativa y política gestora, adaptable a cambios, como el uso turístico del patrimonio dañado y en rehabilitación. También otros elementos, como los productivos, con variados agentes, vías inversoras, etc. Otra baza es climática, con una temperatura media de $17{ }^{\circ} \mathrm{C}$ y cerca de 3.000 horas de insolación, que aportan la denominación de ciudad del sol. Junto a ello el emplazamiento geográfico, estratégico entre vías de comunicación esenciales, elemento clave del desarrollo histórico y reciente.

En la economía es clave el sector agroalimentario, con más de la mitad del porcino de Murcia, la confección, productos minerales no metálicos $\mathrm{y}$ transformación de metales, curtidos, alfarería y unos servicios y distribución que han experimentado el mayor auge reciente, pues atienden a la comarca y a la provincia de Almería. Es clave el sector turístico, mejor posicionado cada vez por la implantación de nuevas tecnologías. Unido al crecimiento económico está el de la población, con cerca de un tercio en el último cuarto de siglo, hasta superar los 92.000 habitantes totales, y convertir a la ciudad en la tercera más poblada de la Comunidad. Se ha debido a la inmigración ecuatoriana y marroquí, más boliviana y rumana, con un inmigrante por cada cinco residentes. La eclosión urbana ha conllevado la atención a la planificación de la expansión, y a las actividades nuevas: turística cultural, aprovechando los años de bonanza; universitaria, con la creación de un campus participado por las dos universidades regionales, de ciencias de la salud, y artesanía, beneficiada por la incorporación de tecnología, diseño y asociacionismo para adaptarse a los mercados, a la internacionalización.

El despegue turístico aprovecha el patrimonio histórico, un conjunto patrimonial básico relacionado con el castillo-fortaleza, el emblema e imagen militar, y el elemento con nivel de funcionalidad turística principal por su capacidad de atracción. El complementario es muy amplio, y además rehabilitado, que dará opción a mostrarlo en 2016. Además, una oferta que ha mostrado su capacidad de atracción es la de actividades culturales, como la reciente del casco antiguo.

Entre las debilidades internas destaca la incidencia de la crisis económica, que se sumó a las consecuencias del terremoto sobre negocios, viviendas, etc. Según el Consorcio de Compensación de Seguros, implicó el cierre total o temporal de 2.000 comercios del casco urbano, y causó desperfectos sobre viviendas valorados en 70 millones de euros. Como respuesta, repuntó el sector de la construcción y los asociados. La conjunción de crisis económica y terremoto aportó otra crisis, la social, que limitó fondos para otras necesidades. Para el Instituto Nacional 
de Estadística, entre los municipios nacionales de tamaño medio (más de 50.000 habitantes), Lorca es el tercer enclave nacional con más elevado riesgo de pobreza de la población $(38,3 \%)$, fruto de unos índices de desempleo mantenidos en los últimos años, entre el $15 \%$ y $19 \%{ }^{19}$. El desempleo y la crisis social han ocasionado pérdida de población, pues entre 2012 y 2015 la ciudad perdió 1551 habitantes. También es preciso destacar la baja cualificación laboral de la población inmigrante, hecho extensible a la mano de obra del sector turístico, que obliga a replantear y dignificar la formación profesional en hotelería (CARM, 2009), y al sector artesanal declararlo área de interés e insertarlo en un polo de concentración (CARM, 2009).

De otro lado, la repercusión del papel histórico de frontera otorgado al turismo cultural no ha tenido los resultados comparativos de Caravaca de la Cruz, donde el emblema de la Cruz de Caravaca en la conquista territorial cristiana y amparo de la cristiandad tiene repercusión incluso mundial, con la consecuente atracción turística. Al margen del castillo-fortaleza, único elemento con nivel de funcionalidad turística principal, la función primaria musealizada otorgada al Conjunto Histórico-Artístico queda en un plano menor de la de-

19 http://www.expansion.com/economia/2015/09/16 manda. A ello se une el deterioro del casco histórico, espacio fundamental del paisaje urbano, por su riqueza arquitectónica, y que padece un bajo interés para el comercio tradicional y primera vivienda, con unas causas que trascienden el problema de deterioro físico de los inmuebles por antigüedad. El menor repunte turístico tiene que ver, también, con la dispersión del patrimonio y, sobre todo, con su discontinuidad espacial con la fortaleza (Figura 11). La ciudad está formada por barrios con fuerte identidad diferenciadora, pero con escasa comunicación física adecuada, especialmente con el casco antiguo, hecho que plantea la conveniencia de la proliferación de rutas.

Por otro lado, la adaptabilidad del producto al turismo de catástrofes ha mostrado claras limitaciones de demanda. Además, no se ha contemplado una planificación social-turística y territorial, y el uso de un producto principal deja fuera los recursos de la esfera geográfica y sus efectos sectoriales. El castillo de Lorca es el mirador para interpretar la vega, los nuevos regadíos y las sierras circundantes, especialmente las cercanas de la Torrecilla y la Tercia, con espacios naturales protegidos cerca del centro urbano, que permiten la transición rápida desde el casco histórico hasta un espacio ZEPA (zona de especial protección para las aves) a poco más de un kilómetro (Secretaría de Estado 


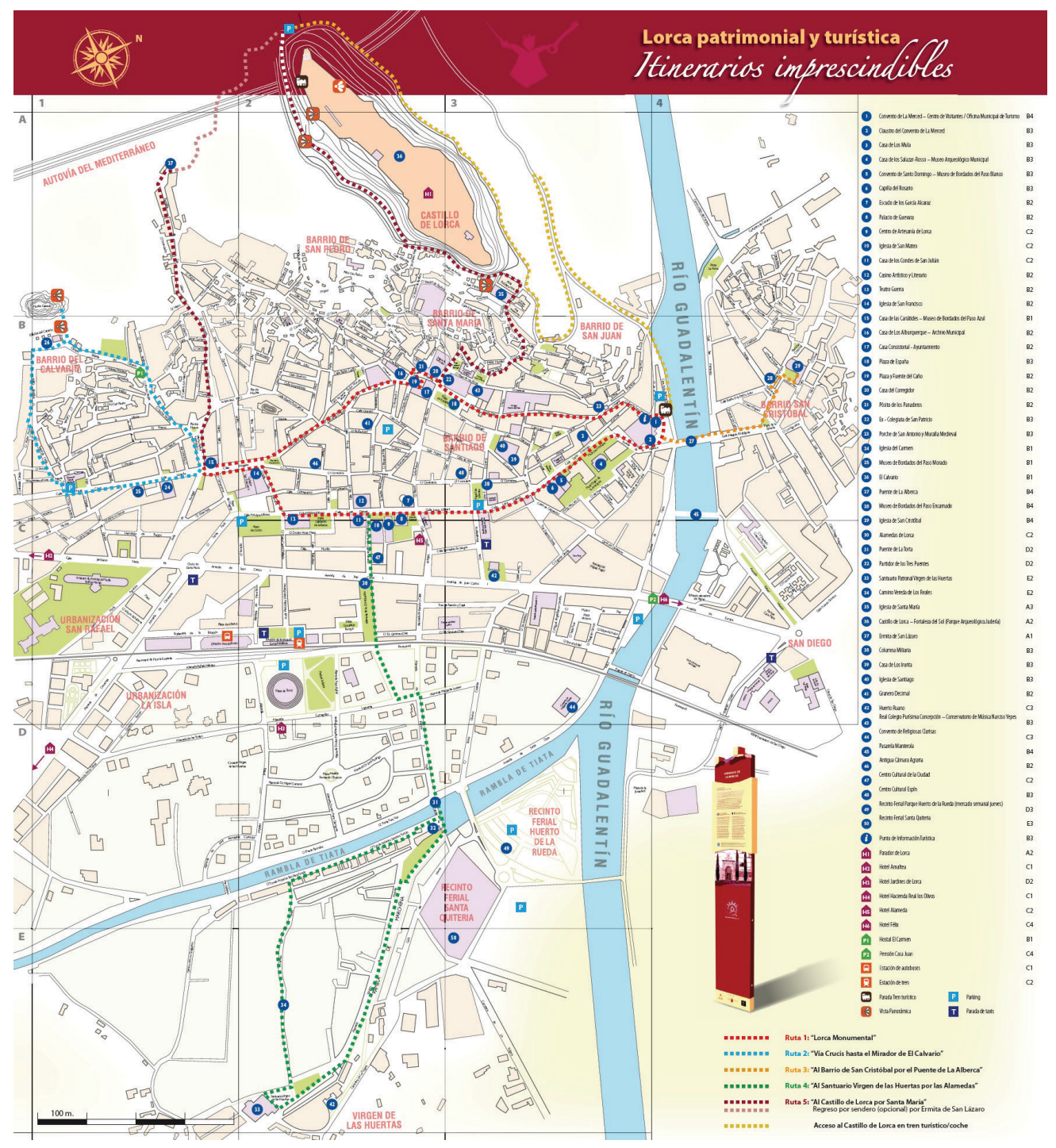

Figura 11. Rutas Monumentales

Fuente: Ayuntamiento de Lorca.

de Cultura, 2015). Y la ciudad, con barrios adaptados a una orografía accidentada, periferia combinada con huertos, agraria y residencial, con edificaciones que siguen un patrón lineal a los bordes de los caminos, y un núcleo con paisaje de población compacta (Dirección General de Urbanismo y Ordenación del Territorio, 2009).

El resultado es un conjunto de recursos ofrecidos que han alumbrado un pro- 
ducto consumible en un recorrido el mismo día. Es cierto que la recepción, aun siendo superior a la esperada, es inferior a la de competidores próximos. El turista mayoritario es nacional y de cercanía, y las estancias reducidas, a excepción de semana santa. La demanda de acogida es rígida, mientras se pierde capacidad de alojamiento y la oferta de calidad se localizada en el parador. Además, la producción y el consumo turístico no es anterior al desplazamiento, con baja representación de viajes organizados y estancias.

El análisis externo también marca las fortalezas previsibles y las debilidades palpables.

Tabla 2. Análisis externo

\begin{tabular}{|l|l|l|}
\hline & \multicolumn{1}{|c|}{ FORTALEZAS } & \multicolumn{1}{c|}{ DEBILIDADES } \\
\hline & - Salida de la crisis económica & - Riesgos naturales \\
& - Actuación institucional regional & - Fortalecimiento de competido- \\
res próximos y de sol y playa & Cosicionamiento estratégico & \\
ANÁLISIS & - & Esfera geográfica cercana \\
EXTERNO & - Oferta de intercambios culturales & \\
& - Conexiones futuras & \\
& - Estrategia del paisaje & \\
\hline
\end{tabular}

Fuente: Elaboración propia.

Entre las fortalezas está la potencial salida de la crisis económica, que permitirá reducir niveles de desempleo y agilizar inversiones. Será vital el papel de la Comunidad Autónoma en relación con el turismo, pues contempla como objetivo general el desarrollo de las actividades turísticas, sobre todo en segmentos y productos de mayor valor añadido, más allá del clásico sol y playa, cuyas principales actuaciones, recogidas en el Plan de Fomento del Turismo de la Región de Murcia CARM (2009), pueden ser retomadas. Además, el posicionamiento estratégico, ahora con la incorporación de un nuevo lema (Lorca. Lo bordamos), y la posibilidad de aprovechar parte del turismo cultural regional futuro, tras la reciente disolución de la sociedad Caravaca Jubilar, por acumular pérdidas cercanas al millón de euros. Cabe mencionar, igualmente, la posibilidad de incorporar una esfera cultural y geográfica cercana. Y el nuevo posicionamiento, que debería conllevar la afiliación o realización de convenios con entidades e instituciones para celebrar exposiciones temporales e intercambios parciales con museos, que dinamizarían las actividades culturales. 
Las conexiones externas son un agente clave del sistema turístico. El corredor del Guadalentín es una de las áreas más transitadas de la región, con la $\mathrm{A} 7$, que conecta los valles del Guadalentín y Segura, articulándolos en torno a la capital regional, más los engarces con Almería y Granada, y ramales hacia las áreas de costa. Es la razón que aporta el problema de la densidad de tráfico (más de 30.000 vehículos diarios), que complica el acceso a Lorca. En transporte, la ciudad cuenta con un servicio de autobuses interurbanos que le permite recibir a más 600.000 pasajeros/año; pero la gran baza está en la línea de la Red Ferroviaria de Interés General, integrada en el Corredor Mediterráneo de Alta
Velocidad, que conectará Almería con el Corredor, y con la Línea de Alta Velocidad Madrid-Castilla La Mancha-Comunidad ValencianaRegión de Murcia (Figura 12), que supondrá la inserción de la ciudad en uno de los más potentes ejes europeos de desarrollo económico, el Arco Mediterráneo (CARM, 2007). La rapidez de desplazamiento está garantizada, y todo dependerá del precio. Se cuenta con la experiencia de la ciudad de Cuenca, a 23 minutos de Albacete y coste de 11 euros/billete. Con esa proporción mantenida llegarían a Lorca más turistas culturales, pues la conexión a la red de Alta Velocidad indica unas previsiones regionales de demanda superiores a 1,5 millones de viajeros/año. Junto a ello, el aero-

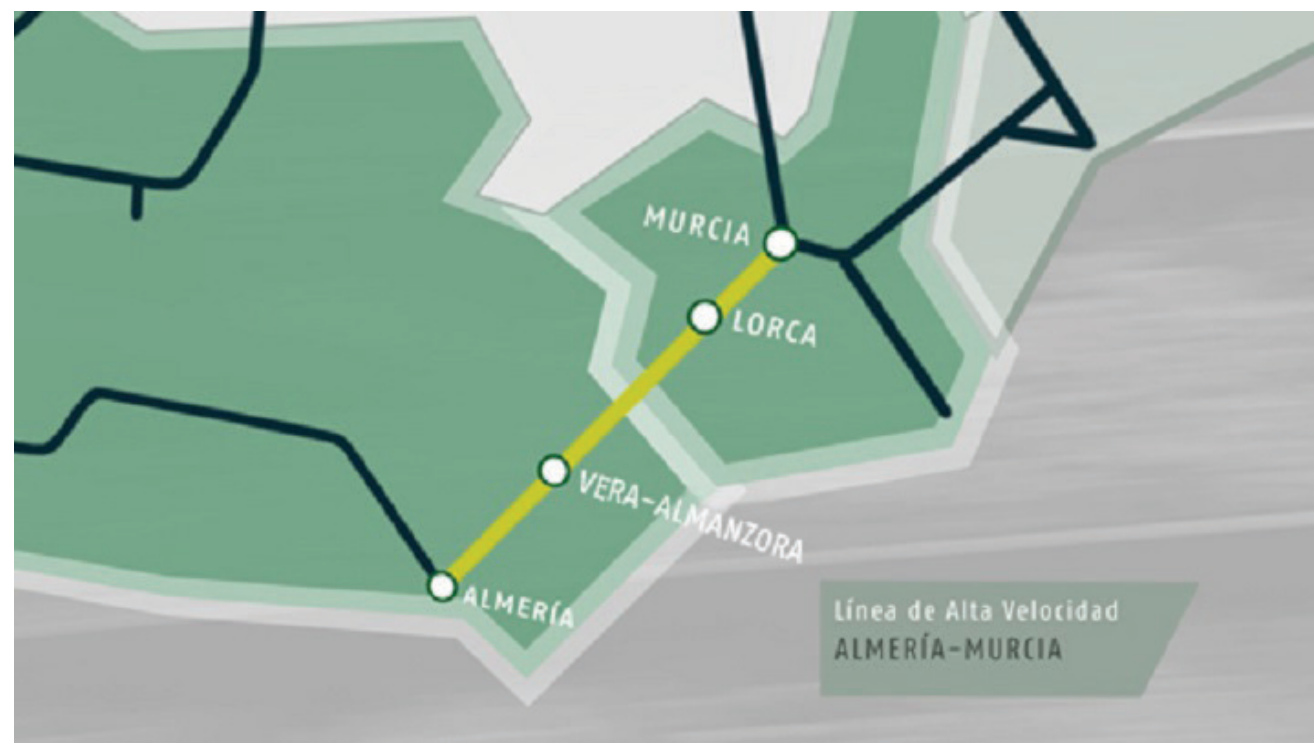

Figura 12. Croquis de infraestructura de alta velocidad (AVE)

Fuente: ADIF, Administrador de Infraestructuras Ferroviarias (2014), Ministerio de Fomento. 
puerto de Corvera (internacional de la región de Murcia), acabado y sin vuelos, pero futura puerta de entrada turística al sureste.

Una última fortaleza puede estar en los resultados del Convenio Europeo del Paisaje (2000), que aportaría fondos europeos para el desarrollo del turismo urbano y rural, y en la adhesión española en 2008, ahora con fondos nacionales, si bien los comunitarios llevan tiempo estancados y los nacionales se han visto menguados por la crisis económica, a excepción de los destinados a paliar los efectos del terremoto.

Entre las debilidades siguen presentes los riesgos naturales, por la ubicación urbana en un área sísmica de las más activas del país. De otra parte, no se han valorado adecuadamente los destinos turísticos culturales próximos, maduros y más competitivos, en gran medida nutridos de viajes organizados. Así, Cartagena Puerto de Culturas dispone de una alta capacidad de atracción sobre el turismo de la Manga del Mar Menor (Cebrián, 2005); está integrado en la ruta mediterránea de cruceros, con 116 escalas anuales, que aportan 170.000 pasajeros, británicos y alemanes, y ofrece la esfera geográfica, el patrimonio minero (con previsión de conjuntarlo con yacimientos paleontológicos, monasterios...) y defensas militares extraurbanas, el Parque Regional de Calblanque, etc.
En segundo lugar, Caravaca Ciudad Santa, que aprovecha la proyección internacional de la Vera Cruz, que en años santos ya celebrados se ha acercado al millón de visitas (Cebrián, 2014), y que en el próximo (2017) espera repetir, incluso incrementando la cifra; la contribución de la cruz, como indica la leyenda, frente a las invasiones árabes, su aportación al territorio de frontera; además, la esfera geográfica aporta las internacionalmente reconocidas pinturas rupestres (Patrimonio de la Humanidad, dentro del Levante español) y turismo de naturaleza (Cebrián, 2008). Por último, la capital regional incorpora el rico patrimonio material e inmaterial, centralidad y comunicaciones, servicios, oferta museística, turismo de congresos..., con la captación de una parte programada de visitantes anteriores, turismo de sol y playa, extranjeros residentes en la costa... En última instancia, la inversión hotelera prevista a corto plazo en la Comunidad se estima en 150 millones de euros, pero se centrará básicamente en la costa.

Por su parte, las conexiones actuales de ferrocarril indican que el Talgo Lorca-Montpellier mantiene datos de uso estabilizados, como en sentido contrario, Barcelona-Sants. Situación inversa plantea la línea Murcia-LorcaÁguilas, que debe ser replanteada, pues el primero de los trayectos padece disminución de viajeros, mientras el de Murcia-Águilas es la única línea 
regional con ascenso. Para la sociedad 'Renfe Viajeros' las tres líneas regionales de cercanías perdieron 800.000 pasajeros en 2012-2014, la mayoría ocasionales, generalmente turistas.

Para concluir, algunas propuestas de mejora, que se convierten en prioridades propias y en necesidades para competir con los proyectos turísticos culturales próximos.

- La ampliación del campus universitario, ya prevista, pues la cifra de 400 alumnos actuales obstaculiza la realización de otras actividades complementarias (congresos, jornadas...), que se verían relanzadas.

- La intervención rápida sobre el casco histórico, que para el Plan Director del Patrimonio de Lorca debería formar parte de un Plan de Calidad del Paisaje Urbano de Lorca, que debe incluir: la defensa patrimonial, reutilización recuperando su función residencial, inserción de servicios y equipamientos básicos, revitalización comercial y conexión con la política turística (Secretaría de Estado de Cultura, 2015).

- La conexión urbana con el castillo, tarea compleja, porque la ciudad dispone de pocos ejes transversales, y los existentes están mal aprovechados. La alternativa podría ser una alameda, típica de la ciudad, pero desaparecidas casi todas, desde el barrio de la Virgen de las Huertas (Secretaría de Estado de Cultura, 2015).
- El relanzamiento de las actividades culturales, sobre todo de aquellas con mayor efecto sobre la población residente y la turística de Murcia, incluidas las desarrolladas en otros idiomas. Esta opción requeriría la resolución rápida de frentes previstos: la pertenencia a la Red de Destinos EDEN, por la recuperación patrimonial realizada; la entrada en la Red de Juderías de España; la inclusión de los bordados de Semana Santa en la Lista del Patrimonio Inmaterial de la Unesco, y el aprovechamiento integral de la catalogación de Lorca como ciudad artesana. Para el relanzamiento de las mencionadas actividades sería clave el establecimiento de convenios o alianzas con: las redes de museos que promueven la exposición de fondos propios, como la valenciana; las universidades que ofrecen exposiciones itinerantes, como la de Alicante; las obras sociales de la banca, Telefónica..., que también las aportan; los obispados o cofradías que podrían prestar fondos no visitables; etc. El material de intercambio es claro, los fondos de los museos de bordados de los Pasos Blanco y Azul, que superan claramente las 10.000 piezas.

- En conexión con la citada necesidad de intervención en el casco histórico, urge el relanzamiento del proyecto de barrio artesano, orientado a su dinamización económica y social, mostrando la tradición de la cerámica, en talleres y museo. A la dinamización 
ayudaría un convenio con la Ruta artesanal, emplazada en los cascos antiguos de la comarca del Noroeste de Murcia, de forma rotativa un domingo en cada cabecera municipal, y que podría ser aprovechado en Lorca un sábado mensual.

- Por último, se precisa la incorporación de la esfera geográfica; para ello se propone aunar el patrimonio existente con el religioso y de naturaleza. $\mathrm{El}$ atractivo circundante presenta limitaciones, y habría que plantearse la ligazón con dos enclaves, en Alhama, a través de fórmulas similares a las de Cartagena Puerto de Culturas, con La Unión. El santuario de La Santa es uno de los cinco permanentes de la región (tres más ya son ofrecidos por el resto de proyectos culturales de la región), y además puerta de entrada al parque regional de Sierra Espuña, galardonado por su gestión como reserva forestal y cinegética y por la innovación turística (Cebrián, 2014, Biblioteca Virtual), con acceso de camino a Lorca, desde la A 7. Para esta posibilidad, y para aplicación de las sugerencias precedentes, sería deseable aprovechar un nuevo marco, el Convenio Europeo del Paisaje, que sitúa en primer plano de las políticas europeas y nacionales al patrimonio cultural, como parte integrante del medio y como elemento clave de la ordenación territorial. En las estrategias de aplicación pueden resultar de suma utilidad las directrices para la comarca del Noroeste de Murcia en lo concerniente al paisaje como elemento patrimonial y su potencial turístico (Fernández et al., 2009).

\section{Referencias}

Cartagena Sevilla, J. C. (2012). Incidencia de los terremotos en el conjunto monumental de Santo Domingo (Lorca, Murcia). Alberca, 10, 143-171.

Cebrián Abellán, A. et al. (2002). La actividad turística patrimonial en la organización del territorio. En A. Cebrián (Coord.). Turismo cultural y desarrollo sostenible. Análisis de áreas patrimoniales (págs. 47-70). Murcia: Universidad de Murcia.

Cebrián Abellán, A. (2004a). Actuaciones institucionales y turismo cultural. Revista de Economía, Sociedad, Turismo y Medio Ambiente, RESTMA, 4, 29-56.

Cebrián Abellán, A. (2004b). Políticas institucionales y turismo cultural. El ejemplo de la Comunidad de Murcia. Cuadernos de Turismo, 13, 7-26.

Cebrián Abellán, A. (2004c). Los proyectos de turismo cultural permanentes y temporales en la Comunidad de Murcia. Cuadernos de Turismo, 14, 7-26.

Cebrián Abellán, A. (2005). Cartagena, Puerto de Culturas: nuevo destino turístico complementario a la Manga del Mar Menor. Ágora, V(2), 265-280. 
Cebrián Abellán, A. (2006). Caravaca de la Cruz, Ciudad Santa (Murcia, España): eje central de destino turístico. Ágora, 12(2), 9-29.

Cebrián Abellán, A. (2008). Patrimonio histórico del Noroeste de Murcia. En Turismo en espacios rurales y naturales. Atlas Nacional de España, Serie Monografías. Cap. III. Turismo y desarrollo en el mundo rural (p. 181-182). Madrid: Centro Nacional de Información Geográfica. Ministerio de Fomento-Instituto Geográfico Nacional.

Cebrián Abellán, A. \& García Marín, R. (2014a). Del turismo religioso a las peregrinaciones permanentes: diversificación turística en el sureste español. Cultur. Revista de Cultura e Turismo, 8(2), 3-30.

Cebrián Abellán, A. \& García Marín, R. (2014b). El Parque Regional de Sierra Espuña (Murcia): eficacia ambiental (PEFC, GFS) y turística (Q). En Conflictos de poder sobre el espacio: historia, naturaleza y gestión. Manual de ordenación territorial a diferentes escalas. México-Málaga: Editorial Eumed.net (Biblioteca Virtual de Derecho, Economía y Ciencias Sociales). Recuperado de: http://www.eumed.net-gratis/2014/1409/index.htm

CARM (1997a). Estudio y diagnóstico de la oferta y demanda turística de la región de Murcia. Murcia: Dirección General de Turismo de la Región de Murcia.

CARM (1997b). Desarrollo del producto cultural de Lorca. Murcia: Dirección General de Turismo de la Región de Murcia.

CARM (2007). Análisis, Diagnóstico y Propuesta de Actuaciones sobre el Paisaje de la Comarca del Valle del Guadalentín de la Región de Murcia. Murcia.

CARM (2008). Estrategia de Paisaje de la Región de Murcia. Murcia: Dirección General del Territorio y Vivienda.

CARM (2009). Atlas de los paisajes de la Región de Murcia. Murcia: Consejería de Obras Públicas y Ordenación del Territorio.

CARM (2012). Plan Estratégico de la Región de Murcia (2014-2020). Murcia. Concejalía de Turismo y Estadística (2015). Lorca. Lorca: Ayuntamiento.

Consejería de Economía y Hacienda (1998). Orden de 7 de octubre de 1998. Murcia: Boletín Oficial de la Región de Murcia. Estatutos del Consorcio para el desarrollo turístico y cultural de Lorca. Murcia: Comunidad Autónoma de Murcia.

Consultur (1996). Plan de desarrollo turístico de la Región de Murcia. Murcia.

Dios de la Hoz, J. de (2012). Terremoto en Lorca: consecuencias y actuaciones sobre el patrimonio religioso. Patrimonio Cultural de España, 6, 107-120.

Dirección General de Urbanismo y Ordenación del Territorio (2009). Atlas de los paisajes de la Región de Murcia. Murcia.

Fernández Muñoz, S., Galiana Martín, R. \& Mata Olmo, R. Directrices de ordenación del paisaje de la comarca noroeste de la región de Murcia. En J. Busquets Fábregas \& A. Cortina Ramos (coord.) (2009). Gestión del Paisaje. Manual de protección, gestión y ordenación del paisaje (pp. 493-508). Barcelona: Ariel.

Impactur (2013). Estudio del impacto económico del turismo sobre la economía y el empleo de la Región de Murcia. Murcia: Instituto de Turismo de la Región. 
Instituto Geológico de Cataluña-Universidad Politécnica de Cataluña-Asociación Española de Ingeniería Sísmica-Generalitat de Cataluña (2011). El terremoto de Lorca del 11 mayo de 2011. Barcelona: Monografía Técnica.

Jiménez, J. F. \& Picazo, H. (2003). Lorca Taller del Tiempo. Lorca: Lorcatur.

Lirón, M. ${ }^{a}$ A. (2012). La importancia del patrimonio cultural en el desarrollo económico de Lorca: el caso de Lorca Taller del tiempo. Patrimonio cultural de España. Patrimonio en riesgo: seísmos y bienes culturales, 6, 137-146.

Martínez Rodríguez, A. (2004). Lorca, ciudad amurallada. Alberca, 2, 139-166.

Murciaturística (2011). Estrategias de desarrollo turístico de la Región de Murcia 2010-2015. Portal turístico de la Región de Murcia. Recuperado de: www.murciaturistica.es.

Plan de dinamización del producto turístico de Lorca. Recuperado de: http://www.expansion.com/economia/2015/09/16.

Región de Murcia (2015). Unidad de Estudios y Estadísticas. Murcia: Comunidad Autónoma de la Región de Murcia.

Secretaría de Estado de Cultura (2015). Plan de Calidad del paisaje urbano de Lorca. Ministerio de Cultura, Madrid. Recuperado de: http://www.paisajeculturaldelorca. ecoproyecta.es/

Segado Bravo, P. (2012). El patrimonio artístico y cultural de Lorca. Patrimonio cultural de España. Patrimonio en riesgo: seísmos y bienes culturales, 6, 123-136.

Troitiño, M. A., García, M. \& Calle, M. de la. Turismo y ciudad histórica: metodología de análisis a escala local. En Turismo y cambio territorial ¿eclosión, aceleración, desbordamiento? IX Coloquio de Geografía del Turismo, Ocio y recreación (pp. 665-696). Zaragoza: Prensas Universitarias de Zaragoza.

Troitiño Vinuesa, M. A. (2007). Estrategias sostenibles en destinos patrimoniales. De la promoción a la gestión integrada e innovadora. Estudios Turísticos, 172-173, 225-231.

Unidad de Estudios y Estadísticas (2013). Estudio sobre el comportamiento de la demanda cultural en la Región de Murcia. Murcia: Región de Murcia.

Vera, J. F. \& Dávila, D. (1995). Turismo y patrimonio histórico cultural. Estudios Turísticos, 126, 161-178. 
Recepción: 26 de junio de 2015

Evaluación: 28 de septiembre de 2015

Aprobación: 11 de noviembre de 2015 